\title{
THE PREVALENCE OF CARDIOVASCULAR DISEASE IN LAGOS STATE, NIGERIA
}

\author{
RASHEED KOLA OJIKUTU \\ Department of Actuarial Science and Insurance \\ University of Lagos, \\ Akoka, Lagos, Nigeria. \\ Email:kolaojikutu@yahoo.com
}

\begin{abstract}
The analysis, which examines the prevalence of cardiovascular diseases (ICD 9: 390-459) in Lagos State of Nigeria, was based on records obtained from the register of deaths in four Local Government Areas of the State. The result shows that there is general increase in death rates due to cardiovascular diseases over the five year period (2000-2004). It was also discovered that the Proportional Mortality Ratio (PMR) for cardiovascular disease was elevated in men (PMR =103; 95\% CI= $96-110$ ) while there was deficit in female deaths (PMR=98; 95\% CI = 91 - 104). The highest cardiovascular death rate was recorded among those in the $60-70$ years age bracket. The PMR in that group is also the highest (PMR=139; 95\% CI=123 - 155) among the various age groups. Data on seven occupational categories show elevated mortality with workers in private sector (PMR $=135 ; 95 \% \mathrm{CI}=61-238$ ) and Civil Servants (PMR=132; 95\% $\mathrm{CI}=109$ - 157) recording the highest in that order while highly significant deficit was recorded among students (PMR=76; 95\% CI = 60 -95)
\end{abstract}

KEY WORDS: Cardiovascular disease, Gender Differentials, Mortality Rates, Occupational Variability, Life Expectancy Ratio

\section{INTRODUCTION}

The last century has witnessed striking rise in health problems for the human species although life expectancy has increased from a global average of 46 years in 1950 to 66 years in 1998.The health status and disease profile of human societies are attributable to the level of their economic development and social organization (Yusuf et al.,2001). This, according to research studies may be due to the fact that most countries at their early stage of development suffer from nutritional and infectious diseases. With industrialization and improvement in nutrition, non-communicable diseases have become even preponderant with cardiovascular and cerebrovascular diseases recording the highest mortality levels, especially for those below the age 50 (WHO, 1999).

A World Health Report (1999) observes that taken together, non-communicable diseases contribute about 59 per cent of global mortality ( 31.7 million deaths) and 43 per cent of global burden of disease in 1998. It explains further that over 17 million people are killed by cardiovascular and cerebrovascular diseases every year; a substantial number of which is caused by tobacco smoking and poor diet. It observes that the risk increases with age and it is greater for women than men. Yusuf et al (2001), citing from the World health Report (1999), estimated that in 1998, 78 per cent of the burden of non-communicable and 85 per cent of the cardiovascular and cerebrovascular disease burden may come from low and middle income countries. According to them, high burden of diseases in developing countries is attributable to urbanization and the related high risk factors such as obesity, diabetes, hypertension and other such diseases.

Researchers such as Reddy and Gruson (2003) explain that in economically stable countries, death from cardiovascular and cerebrovascular diseases come from long and productive life, whereas in developing countries almost half of such deaths occur among people in the prime of 
their working lives. As a result, their deaths are not only tragedies to their families but also impact negatively on the course of economic growth in those countries. While explaining that these deaths are preventable, Reddy and associates (2003) posit that as an area urbanizes, the population tends to lead a sedentary lifestyle, experience high level of stress and consume unhealthy food. Comparing this with the situation in the developing world, Robertson (2004) reviewed heart diseases and stroke in the United States of America and rated them as the first and the leading causes of death for both men and women in that country. The American National Center for Chronic Disease Prevention and Health Promotion puts mortality due to these two diseases in that country at 950,000 persons per year. This, they say translates to one American death every 33 seconds. It is observed that one fourth of the American population has some form of cardiovascular problem and there are about six million hospitalizations each year as a result of cardiovascular disease.

Studies show that out of about 50 million deaths that occur in the world, about 40 million occur in the developing countries, a substantial part of which is due to cardiovascular diseases. It is projected that by 2025 , over 80 per cent of all cardiovascular diseases in the world will occur in low income and middle income countries (Yusuf, et. al, 2002). In addition to this, Gruson (2003) submits that in 2001, tobacco alone generated approximately 30 per cent of cardiovascular deaths worldwide while an estimate of about 4.4 million deaths were caused by high cholesterol level and nearly 38 per cent of men and 21per cent of women consume more than the recommended daily benchmark of alcohol. According to Vasianovich and associates (2008), this daily benchmark is fixed at 21 units per week where a unit is half a pint of normal strength beer, a small glass of wine, or a single measure of spirits and a daily consumption of 4 or more units a day for men. Any quantity above this is likely to result in increasing health risk for individuals.

Supporting this position, Sheikh (2003) explains that in 1998 smoking accounted for 4.5 million cardiovascular deaths as it increases the risk of dying from coronary heart disease. He observed that smoking cessation is the most cost effective intervention for patients with cardiovascular and cerebrovascular diseases. According to him, one billion people across the world are now overweight and obese, leading to fear that obesity will rapidly overtake tobacco smoking lifestyle risk factor for heart disease

Research studies suggested a minimum alcohol consumption of 21 units per week (where a unit is defined as half a pint of normal strength beer, a small glass of wine, or a single measure of spirits). They observed that regular drinking of 4 or more units a day for men is likely to result in increasing health risk and is not advisable (Vasianovich et al, 2008)

Tracing the causes of mortality in Africa for 2001 and 2002, Ssemakula (2002) observed that communicable diseases continue to be the principal cause of mortality in Africa. Citing World Health Report (2002), Ssemakula explained that though, basic health indicators for Africa were typical for developing countries, yet the situation in Africa shows that a relatively small number of risks cause a large number of premature deaths and account for a very large share of global burden of disease.

Muna (2003), supporting the position of the World Heart Foundation, posits that there is a strong indication that the spectrum and pattern of cardiovascular disorders in Africa is such that classic risk factors appear to be on the rise and it may equal or exceed those in many developed countries. Comparing the rural and urban areas of Africa, he explained that hypertension is the most common public health problem in Africa and it comes with complications such as stroke, heart failure and renal diseases. According to him, the frequency of hypertension is about 5-10 percent in rural Africa, compared to about 12 per cent in most urban areas. In his opinion, the change and modification in lifestyle, risk prone behaviour, diet, cultural attitudes and certain other consequences of rapid urbanization and demographic tendencies are probably responsible for the observed trends. 
One major problem militating against in-depth understanding of the pattern of cardiovascular and cerebrovascular diseases in Africa, particularly in Nigeria, is the dearth of research studies and literature in the subject area. Ogungbo et al (2003) reported that twenty six papers have been published on stroke in Nigeria from 1962 to 2000 and that the most authoritative of them was the paper by Oshuntokun (1977) which confirms a male preponderance in strokes as high as 3:1 in hospital reports and 5:2 in community survey. The probability that a man or a woman dies from a non-communicable disease is higher in Sub-Sahara Africa than other developing countries. Worldwide, in 1990, non-communicable diseases were responsible for 28.1 million deaths with cardiovascular disease (6.3 million deaths), cerebrovascular accidents (4.4 million deaths), and lower respiratory infection (4.3 million deaths) as the leading causes of death (Murray et al, 2004)

In view of the above outlined global trend in mortality resulting from non-communicable diseases, the present paper intends to examine the prevalence of cardiovascular diseases among the residents of Lagos State, Nigeria with special focus on gender, age and occupational category. The paper is divided into five sections. Section 1 is on introduction, Section 2 explains the study population, Section 3 discusses the research methodology, Section 4 analyses the collected data while Section 5 is on conclusion.

\section{METHODOLOGY}

\section{The Study Area}

The data for the analysis was drawn from four out of twenty-four local government areas in the Lagos State of Nigeria as statutorily recognized by the 1999 constitution of the Federal Republic of Nigeria. Lagos State was created on the $27^{\text {th }}$ of May 1967 by Decree Number 14, which merged the then Federal Capital of Nigeria with the old colony province of the then Western Region of Nigeria to form a new state. The State lies approximately between longitudes $2^{\circ} 42^{\prime}$ East and 3042'East and latitudes 6 $6^{\circ} 22^{\prime}$ North and 6 ${ }^{\circ} 2^{\prime}$ North. It is bounded in the South by the Guinea coast about $180 \mathrm{~km}$ along the Atlantic Coastline, in the West by the Republic of Benin and in the North and East by Ogun State (Odumosu, Balogun and Ojo ,1999). Lagos State has a total area of 3,577 sq km about 22 per cent of which is water (Oke and Ahuchogu, 2000). Despite its position as the smallest State in the Federation in terms of land mass, occupying only about 0.4 per cent of the area of Nigeria, it has gone through series of administrative transformations into a frontline position among the thirty-six states making up the Federation of Nigeria.

Lagos State, with a population of 9,013,534 million, comprising 4,678,020 males and 4,335,514 females, is the most urbanized state in Nigeria. In 1963, the population of Lagos State was $1,444,000$ with 603,000 males and 591,000 females. This grew to 5,725,116 in 1991 with a male population of 3,010,604 and 2,714,512 females. The population density of Lagos State is 2,455 (National Population Commission and National Bureau of Statistics, 2006)

\section{Type of Data}

Data used in this study were extracted from the register of deaths at the Lagos Island, Lagos Mainland, Ikorodu and Epe, which are four local government areas (LGA) chosen randomly from the twenty-four local government areas in the state. It was observed that in all, a total of six thousand two hundred and sixty nine deaths were recorded in the four LGAs from 2000 to 2004. This study used the following variables, namely: Gender, Occupation, Age with the underlying cause of death, that is, cardiovascular disease (ICD 9:390-459) classified according to the $9^{\text {th }}$ revision of the International Classification of Diseases created by the World Health Organization.

\section{Techniques for Data Analysis}


Simple descriptive analysis of distribution of deaths was used and initial tests of significance carried out using $\chi^{2}$. In addition, the Proportional Mortality Ratios (PMR) was calculated by comparing the observed number of deaths due to cardiovascular diseases with the expected number of deaths based on gender, age and occupational categories. The corresponding 95\% confidence intervals (CI) were obtained under the assumption that the observed number of deaths followed the Poisson distribution.

\section{PRESENTATION AND ANALYS OF RESULTS}

\section{Cohort Characteristics}

This study cohort which covers a period of four years (2000 to 2004) consists of a total of six thousand, two hundred and sixty nine (6269) persons who died in Epe, Ikorodu, Lagos Island and Lagos Mainland. Table 1 shows that with respect to cardiovascular problems there is general increase in death rate over the study period. About $23.7 \%$ of those who died in 2000 died of cardiovascular disease while $21.9 \%$ of them died in $2001,24.3 \%$ died in $2002,32.7 \%$ in 2003 and $36.1 \%$ in 2004 . Overall, $26.7 \%$ of the deaths in the four year period are from the cardiovascular group. See Table 1 below.

\section{Table 1: Cause of Death and Year of Death}

\begin{tabular}{|c|c|c|c|c|c|c|c|c|c|c|c|c|c|c|}
\hline & & & \multicolumn{11}{|c|}{ CAUSE OF DEATH } & \multirow[b]{2}{*}{ Total } \\
\hline & & & $\begin{array}{l}\text { INFECTION } \\
\text { AND } \\
\text { PARASITIC } \\
\text { DISEASE }\end{array}$ & $\begin{array}{l}\text { CARDIOVA } \\
\text { SCULAR } \\
\text { DISEASE }\end{array}$ & $\begin{array}{c}\text { CEREBRO } \\
\text { VASCULAR } \\
\text { DISEASE }\end{array}$ & $\begin{array}{l}\text { RESPIRA } \\
\text { TION }\end{array}$ & HIV/AIDS & MATERNAL & OLD AGE & CANCER & OTHERS & ANAEMA & MALARIA & \\
\hline \multirow{15}{*}{$\begin{array}{l}\text { YEAR OF } \\
\text { DEATH }\end{array}$} & \multirow[t]{3}{*}{2000} & Count & 200 & 237 & 170 & 60 & 7 & 32 & 35 & 22 & 197 & 26 & 13 & 999 \\
\hline & & $\%$ within YEAR OF DEATH & $20.0 \%$ & $23.7 \%$ & $17.0 \%$ & $6.0 \%$ & $.7 \%$ & $3.2 \%$ & $3.5 \%$ & $2.2 \%$ & $19.7 \%$ & $2.6 \%$ & $1.3 \%$ & $100.0 \%$ \\
\hline & & $\begin{array}{l}\text { \% within CAUSE OF } \\
\text { DEATH }\end{array}$ & $19.4 \%$ & $14.3 \%$ & $16.5 \%$ & $13.2 \%$ & $12.1 \%$ & $14.2 \%$ & $8.9 \%$ & $18.3 \%$ & $21.2 \%$ & $15.7 \%$ & $8.6 \%$ & $16.1 \%$ \\
\hline & \multirow[t]{3}{*}{2001} & Count & 227 & 307 & 296 & 107 & 19 & 47 & 87 & 28 & 205 & 35 & 46 & 1404 \\
\hline & & $\%$ within YEAR OF DEATH & $16.2 \%$ & $21.9 \%$ & $21.1 \%$ & $7.6 \%$ & $1.4 \%$ & $3.3 \%$ & $6.2 \%$ & $2.0 \%$ & $14.6 \%$ & $2.5 \%$ & $3.3 \%$ & $100.0 \%$ \\
\hline & & $\begin{array}{l}\text { \% within CAUSE OF } \\
\text { DEATH }\end{array}$ & $22.0 \%$ & $18.5 \%$ & $28.7 \%$ & $23.5 \%$ & $32.8 \%$ & $20.9 \%$ & $22.1 \%$ & $23.3 \%$ & $22.1 \%$ & $21.1 \%$ & $30.5 \%$ & $22.6 \%$ \\
\hline & \multirow[t]{3}{*}{2002} & Count & 281 & 430 & 372 & 131 & 18 & 81 & 127 & 39 & 188 & 46 & 55 & 1768 \\
\hline & & $\%$ within YEAR OF DEATH & $15.9 \%$ & $24.3 \%$ & $21.0 \%$ & $7.4 \%$ & $1.0 \%$ & $4.6 \%$ & $7.2 \%$ & $2.2 \%$ & $10.6 \%$ & $2.6 \%$ & $3.1 \%$ & $100.0 \%$ \\
\hline & & $\begin{array}{l}\text { \% within CAUSE OF } \\
\text { DEATH }\end{array}$ & $27.3 \%$ & $25.9 \%$ & $36.1 \%$ & $28.7 \%$ & $31.0 \%$ & $36.0 \%$ & $32.2 \%$ & $32.5 \%$ & $20.2 \%$ & $27.7 \%$ & $36.4 \%$ & $28.4 \%$ \\
\hline & \multirow[t]{3}{*}{2003} & Count & 268 & 525 & 126 & 127 & 12 & 48 & 114 & 18 & 283 & 51 & 33 & 1605 \\
\hline & & $\%$ within YEAR OF DEATH & $16.7 \%$ & $32.7 \%$ & $7.9 \%$ & $7.9 \%$ & $.7 \%$ & $3.0 \%$ & $7.1 \%$ & $1.1 \%$ & $17.6 \%$ & $3.2 \%$ & $2.1 \%$ & $100.0 \%$ \\
\hline & & $\begin{array}{l}\text { \% within CAUSE OF } \\
\text { DEATH }\end{array}$ & $26.0 \%$ & $31.6 \%$ & $12.2 \%$ & $27.9 \%$ & $20.7 \%$ & $21.3 \%$ & $28.9 \%$ & $15.0 \%$ & $30.5 \%$ & $30.7 \%$ & $21.9 \%$ & $25.8 \%$ \\
\hline & \multirow[t]{3}{*}{2004} & Count & 55 & 160 & 66 & 31 & 2 & 17 & 31 & 13 & 56 & 8 & 4 & 443 \\
\hline & & $\%$ within YEAR OF DEATH & $12.4 \%$ & $36.1 \%$ & $14.9 \%$ & $7.0 \%$ & $.5 \%$ & $3.8 \%$ & $7.0 \%$ & $2.9 \%$ & $12.6 \%$ & $1.8 \%$ & $.9 \%$ & $100.0 \%$ \\
\hline & & $\begin{array}{l}\text { \% within CAUSE OF } \\
\text { DEATH }\end{array}$ & $5.3 \%$ & $9.6 \%$ & $6.4 \%$ & $6.8 \%$ & $3.4 \%$ & $7.6 \%$ & $7.9 \%$ & $10.8 \%$ & $6.0 \%$ & $4.8 \%$ & $2.6 \%$ & $7.1 \%$ \\
\hline \multirow{3}{*}{\multicolumn{2}{|c|}{ Total }} & Count & 1031 & 1659 & 1030 & 456 & 58 & 225 & 394 & 120 & 929 & 166 & 151 & 6219 \\
\hline & & $\%$ within YEAR OF DEATH & $16.6 \%$ & $26.7 \%$ & $16.6 \%$ & $7.3 \%$ & $.9 \%$ & $3.6 \%$ & $6.3 \%$ & $1.9 \%$ & $14.9 \%$ & $2.7 \%$ & $2.4 \%$ & $100.0 \%$ \\
\hline & & $\begin{array}{l}\text { \% within CAUSE OF } \\
\text { DEATH }\end{array}$ & $100.0 \%$ & $100.0 \%$ & $100.0 \%$ & $100.0 \%$ & $100.0 \%$ & $100.0 \%$ & $100.0 \%$ & $100.0 \%$ & $100.0 \%$ & $100.0 \%$ & $100.0 \%$ & $100.0 \%$ \\
\hline
\end{tabular}

Source: Local Government Death Register, Lagos State.

\section{Sex Differences}

The widespread misconception is that cardiovascular disease is a man's disease. Though, men's lifestyles put them at particular risk of CVD (DHSSPS, 2004), studies also show that as a woman ages her risk of heart decease increases dramatically and that this risk is increased substantially after menopause (Crawford and Johannes, 1999; Gordeski, 2002). It could be inferred there from that men may be more prone to CVD than women at earlier stages of life while women are likely to face higher risk later in life. 
The data show that among those who died of cardiovascular diseases $47.7 \%$ are Females while $52.3 \%$ are males. These figures seem to suggest that more males die of cardiovascular problems than females. To validate this assumption, the hypothesis:

$$
\begin{aligned}
& \mathrm{H}_{01}=\pi_{1}-\pi_{2}=0 \\
& \mathrm{H}_{11}=\pi_{1}-\pi_{2}>0
\end{aligned}
$$

The hypothesis was tested at $5 \%$ level of significance (Where $\pi_{1}$ is the proportion of male who died during the study period and $\pi_{2}$ is the proportion of females who died during the same period) . With $\mathrm{Z}=2.681$, we reject $\mathrm{H}_{01}$. This shows that there is significant difference between the proportion of males and females who died during the period under study (2000-2004) and that the proportion of males who died of cardiovascular disease may be more than the proportion of females who died of the same disease. See Table 2 below.

Table 2: PMR of Observed and Expected Deaths due to Cardiovascular Disease by Sex

\begin{tabular}{|l|l|l|l|l|}
\hline SEX & OBSERVED & EXPECTED & PMR & $95 \%$ CONFIDENCE INTERVAL \\
\hline MALE & 790 & 770 & 103 & $96-110$ \\
\hline FEMALE & 867 & 887 & 98 & $91-104$ \\
\hline
\end{tabular}

$\mathrm{P}<0.05 \quad$ SOURCE: Survey, April, 2007

Table 2 shows that Proportional Mortality Ratio for cardiovascular deaths was elevated in males (PMR =103; 95\% CI = 96 - 110) while there was deficit in female deaths (PMR=98; 95\% CI = 91 -104). This seems to confirm the position of Oshuntokun (1977) that there is a male preponderance of cardiovascular diseases in Nigeria and it also supports the result of the above hypothesis $\mathrm{H}_{01}$.

\section{Age and Cardiovascular Diseases}

Researchers such as Booth and associates (2006), Stauth (2007) and American Heart Association (AHA) (2007) generally agree that the development of cardiovascular problem may be related to age. While identifying the several risk factors of cardiovascular diseases, AHA posits that apart from heredity and gender, over $83 \%$ of people who die of coronary heart disease are 65 years or older. It observes that at older ages, women who suffer from heart attack are more likely to die from them within a few weeks.

In this study, the highest cardiovascular death rate $(33.3 \%)$ was recorded among those in the 60 to 70 years age bracket. This was followed by $31.7 \%$ and $31 \%$ recorded in the 70 to 80 years and 50 to 60 years age categories respectively. This supports AHA (2007), Booth et al. (2006) and Stauth (2007) as explained above. However, the percentages are considerably lower at lower age groups where $11.8 \%$ of those below the age of 1 year and $12.5 \%$ of those between ages 1 and 5 years died of cardiovascular diseases.

The above is further explained by the Pearson $\chi^{2}$ test $(\mathrm{p}=000<0.05)$ in Table 3 which shows that generally in the population of residents of Lagos State, Nigeria, there is significant difference between age and cause of death.

Table 3: Chi- Square for Testing Relationship between Age and Cause of Death Chi-Square Tests

$$
\text { Value Df Asymp.Sig (2 sided) }
$$


Pearson Chi-square

Likelihood Ratio

Association

No. Of Valid Cases

6206

Source : Survey April 2007

Table 4: Proportional Mortality Ratio of Observed and Expected Deaths due to Cardiovascular Disease by Age

\begin{tabular}{|c|c|c|c|c|}
\hline AGE & OBSERVED & EXPECTED & PMR & $\begin{array}{l}\text { 95\% CONFIDENCE } \\
\text { INTERVAL }\end{array}$ \\
\hline Less than 1 year & 2 & 5 & 44 & $4-126$ \\
\hline 1 but less than $5 y r s$ & 8 & 17 & 47 & $20-85$ \\
\hline 5 but less than 10 years & 5 & 12 & 43 & $13-88$ \\
\hline 10 but less than 20 years & 33 & 62 & 53 & $37-73$ \\
\hline 20 but less than 30 years & 155 & 239 & 65 & $55-75$ \\
\hline 30 but less than 40 years & 236 & 286 & 83 & $72-94$ \\
\hline 40 but less than 50 years & 230 & 239 & 96 & $84-109$ \\
\hline 50 but less than 60 years & 270 & 215 & 126 & $111-141$ \\
\hline 60 but less than 70 years & 283 & 204 & 139 & $123-155$ \\
\hline 70 but less than 80 years & 231 & 185 & 125 & $109-142$ \\
\hline 80 but less than 90 years & 139 & 120 & 116 & $98-136$ \\
\hline 90 but less than 100years & 50 & 54 & 93 & $69-121$ \\
\hline 100 years or more & 14 & 20 & 69 & $38-110$ \\
\hline
\end{tabular}

$\mathrm{P}<0.05$

Source: Survey, April 2007

A salient feature in Table 2 is that death due to cardiovascular diseases was significantly reduced at ages below 50 years while PMRs for ages 50 years but less than 60 years (PMR=126; $95 \% \mathrm{CI}=111-114$ ), 60 years but less than 70 years (PMR=139; 95\% CI $=123-155)$, 70 years but less than 80 years (PMR=125; 95\% CI $=109-142$ ), 80 years but less than 90 years (PMR $=116,95 \% \mathrm{CI}=98-136)$ were significantly elevated. The significantly reduced mortality due to cardiovascular diseases at ages 90 and above is noteworthy.

\section{Occupation and Cardiovascular Diseases}

Literature is replete with results on correlation between occupation and cardiovascular disease but direct evidence linking the two is unconfirmed. Kivimaki and associates (2002) in a study on work stress and risk of cardiovascular disease using the high job strain and effort-reward 
imbalance model reported that evidence from industrial employee suggests that attention should be paid to the prevention of work stress. Reed and associates (1989) in a study on occupational strain and incidence of coronary heart disease explained that there is no significant association between the coronary heart disease and the individual job components of high psychological demands and low job control or the high strain interaction of these two characteristics. Table 4 shows that the greatest victims of cardiovascular disease in Lagos State are the traders with $38.9 \%$ of them dying of the disease while workers in the private sector recorded only $0.9 \%$ deaths which are least in the category. Among traders, only $24 \%$ died of cardiovascular disease while the record amongst workers in private sector, housewives and civil servants are $33.3 \%, 29.7 \%$ and $32.5 \%$ respectively.

Table 5: PMR of Observed and Expectation of Deaths Due to Cardio-Vascular Disease by Occupation

\begin{tabular}{|l|c|l|l|c|}
\hline OCCUPATION & OBSERVED & EXPECTED & PMR & $\begin{array}{l}\text { 95\% CONFIDENCE } \\
\text { INTERVAL }\end{array}$ \\
\hline Informal Worker & 107 & 98 & 109 & $89-130$ \\
\hline Businessmen & 49 & 40 & 123 & $91-159$ \\
\hline Trader & 382 & 393 & 97 & $88-107$ \\
\hline Professionals & 50 & 47 & 107 & $79-138$ \\
\hline Civil Servants & 116 & 88 & 132 & $109-157$ \\
\hline Clergymen & 13 & 11 & 115 & $61-185$ \\
\hline Students & 72 & 94 & 76 & $60-95$ \\
\hline Housewives & 46 & 38 & 120 & $88-158$ \\
\hline Workers in sector & 9 & 7 & 135 & $61-238$ \\
\hline Others & 138 & 165 & 84 & $70-98$ \\
\hline
\end{tabular}

Source: Survey, April 2007

Table 5 shows significant elevation in mortality for about seven occupational groups. Informal Workers (PMR =109; 95\% I =89 - 109), Businessmen (PMR=123; 95\% CI = 91 - 159), Professionals (PMR=107; 95\% CI=79 - 138), Civil Servants (PMR=132; 95\% CI=109 - 157), Clergymen(PMR=115; 95\% CI=61 - 185), Housewives (PMR=120; 95\% $\mathrm{CI}=88-158)$ and Workers in private sector(PMR $=135 ; 95 \% \mathrm{CI}=61-238)$. Surprisingly, there is no significant growth in cardiovascular deaths amongst traders (PMR $=97 ; 95 \% \mathrm{CI}=88-107)$ and students (PMR=76; 95\% CI= $60-95$ ).

\section{CONCLUSION}

Research work on the prevalence of cardiovascular diseases in Nigeria is scanty. Osuntokun (1977, cited in Ogungbo et al, 2003) while noting the inadequacies of studies on stroke and other cardiovascular related deceases in Nigeria, observed that research work in these areas are rare. Ogungbo noted that the actual incidence of stroke in Nigeria has not been established because hospital data constitute just a small proportion of information on the disease. Stroke is 
known to be a major cause of morbidity and mortality in the country and it is estimated that every Nigerian knows or is related to someone who has suffered a stroke. It is in view of this perceived limitation that this study decided to use the data obtained from the local government death records to project the prevalence of cardiovascular and cerebrovascular diseases.

The study shows that there is general increase in cardiovascular death rate over the study period (2000-2004) and that there is preponderance of cardiovascular diseases among male members of the population of Lagos State residents as compared to their female counterparts.

Cardiovascular diseases are found to be distributed unevenly across occupational categories with traders recording more fatalities in cardiovascular deaths than any other groups. The study further supports the position of existing research results that the development of cardiovascular diseases may be related to age.

Ojikutu (2007) while examining the urban factors that contribute to high mortality in Lagos State isolated fifteen factors such as migration, education, waste collection, religion, noise pollution, obesity, time management, education of the individual, pressure of work, eating habit and so on were extracted and fourteen of them were found to be functionally related to Cause of Death which is the fifteenth factor. Quoting UNDP (1999), he explained that in 1977, cardiovascular and cerebrovascular diseases were responsible for $50 \%$ of the deaths in the developing countries of the world, including Nigeria. Lagos being one of the largest urban centres in the world with an average population density of about 1,308 persons per sq $\mathrm{km}$ and in some cases density is over 20,000 people per square kilometre has its own share of general urban environmental challenges which puts strain on the health and well being of its residents. Government intervention and general education of the people are therefore imperative for reduction of some of this pressure.

The present situation of cardiovascular disease in Lagos State seems to be more precarious than that of the HIV/AIDS epidemic because whereas most Nigerians may not know or have close relationship with someone an HIV/AIDS sufferer but almost all Nigerians (including Lagosians) know or are close to someone having cerebrovascular or cardiovascular disease.

\section{REFERENCES}

American Heart Association (2007). "Risk Factors and Coronary Heart Disease.! [Online]. Available:, http://www. americanheart.org/presenter.jhtml?identifie $r=4726$. DA: $29^{\text {th }}$ January 2007

Booth, G.L; Kapral, M.K; Fung, K. and Tu, J.V. (2006)."Relation between Age and Cardiovascular Disease in Men and Women with Diabetes Compared with Non-diabetic People: A Population based Retrospective Cohort Study." Lancet, 200 July, Volume 1368 Number 9529: 29-36

Clapp, W. Richard (2006). "Mortality among US Employees of a Large Computer Manufacturing Company:1969-2001: Environmental Health: A Global Access Science." [online] Available: http://creativecommons.org//licenses/by/2.0. DA: 22 ${ }^{\text {nd }}$ February 2007

Crawford, S.L and Johannes, B.C (1999), "The Epidemiology of Cardiovascular Disease in Postmenopausal Women." The Journal of Clinical Endocrinology and Metabolism, Volume 84. Number 6: 1803-1806

Gorodeski, G. (2002). “Update on Cardiovascular Disease in Postmenopausal Women.”Beast Practice and Research in Clinical Obstetrics and Gynaecology, Volume 16, Number 3: 329-355 Gruson, Damien (2003). Cardiovascular disease and homocysteine: A Short Summary of a Long History... Laboratoire de Biochieme14(3)[online]. Available: http:// www.ifcc.org/ ejifcc/vol14No3/ 140310200303n.ht . DA:29th January 2007 
Kivimaki, Mika; Leino-Arjas, Paivi; Ritva, Luukonen; Hilkka, Riihimaki; Vahetra, Jussi and Kirjonen, Juhani (2002). "Work Stress and Risk of Cardiovascular Mortality: Prospects Cohort Study of Industrial Employees." British Medical Journal, 2002, Volume.325, Number 857[online]. Available: http://www.bmj.com/cgi/content/full/325/7369/857. DA: 29/01/2007

Monson, R.R.; Peters, J. M. and Johnson, M.N. (1975)."Proportional Mortality among Vinyl Chloride Workers." Environmental Health Perspectives, Vol. 11: 75-77

Murray, C. J. and Lopez, A. D.(2004). "Mortality by Cause for Eight Regions of the World." (Global Burden of Disease Study). National Library of Medicine [online] Available:

http:/www.ncbi.nlm.nih.gov: DA: 29/1/2007)

Muna, W. F. (2003). Cardiovascular disorders in Africa, Pub Med, National Library of Medicine. [Online]. Available]: http: www.hst.org.za/news/20031207 DA: 29/1/2007

Odumosu, Tayo; Balogun Yinka and Ojo, Kayode (1999). Lagos State in Maps. Ibadan, Nigeria: Rex Charles Publication.

Ogungbo. B. I.; Gregson, B.; Mendelow, A.D.; Walker, R. (2003). “Cerebrovascular disease in Nigeria: What do we know and what do we need to know?" Tropical Doctor, Vol. 33: 25-30.

Ojikutu, R. K (2007). “ Urban Factors in Relation to Mortality Patterns in Lagos State, Nigeria." Journal of Probability and Statistics Volume 1, Number 1: 77-100

Ojikutu, R. K. (2008). "The Relationship between Demographic Characteristics and Death Pattern of the People of Lagos State, Nigeria." Ghana Journal of Development Studies. Volume 5 , Number 1: 1-19

Oke, Olufemi and Victor-Ahuchogu, Julie (2000)-- Report of the In-Depth Assessment in Selected Local Governments - Implementing Aids Prevention and Care Project (IMPACT) USAID, -Family Health International.

Osuntokun, B. O. (1977). "Strokes in the Africans." African Journal of Medicine and Medical Science,Volume 6, Number 2: 39-53

Reed, D. M.; Lacroix, A. Z.; Karasek, R.A.; Miller; D. and Maclean, C.A. (1989). “Occupational Strain and the Incidence of Coronary Heart Disease." American Journal of Epidemiology, Vol. 129, No3: 495-502.

Robertson, Rose Marie (2004). Preventing Heart Disease and Stroke: Addressing the Nation's Leading Killers-2004, US Department of Health and Human Services, Center for Diseases Control and Prevention, USA

Sheikh, Shahryar (2003). Pandemic of Cardiovascular Disease: A Challenge...and...opportunity. [Online]-_Available: http:/circulation.or.kr/workshop/2003/spring/file/workshop.seo.doc DA: 29th January 2007

Stauth, David (2007). "Link Identified Between Age, Cardiovascular Disease Seniors/Aging." Medical News . [Online]. Available : http:// www. medicalnwstoday.com /medicalnews.php?newsid = 55913: DA: 29 ${ }^{\text {th }}$ January 2007 
Ssemakula, Kiwanuka John (2002). "African Health Analysis -Selected data from World Health Report 2002, Medilinks: African Health Report 2002." [Online]. Available: http://www. medilink2. org/ publications /AfricaHealth2002.pdf DA: 29th January 2007

Vasianovich, A.; Teijlingen, E. R.; Reid, G. and Scott, N.W (2008). "Key health promotion factors among male members of staff at a higher educational institution: A Cross-Sectional postal survey." BMC Public Health Volume 8, Number 58.

World Health Report (1999). “Making A Difference.” [Online]. Available: http://www. Who .int/ whr/ 1999/ en/ Downloaded from the Internet: DA: 13 ${ }^{\text {th }}$ March 2005

World Health Organization (2002). Reducing Risks, Promoting Healthy Life. (World Health Report). [Online].Available: http://www.who.int/whr/2002/en/: DA: 4th March 2005

Yussuf, S.; Reddy, S.; Ounpu, S. and Anand, S. (2001). Global Burden of Cardiovascular Diseases, American Heart Association Inc.- [Online]. Available:

http://circ.ahajournals.org/cgi/content/full/104/22/2746: DA: 29th January 2007

Yusuf, S.; Reddy, S.; Ounpu, S. and Anand, S. (2002). "The Global Epidemic of Atherosclerotic Cardiovascular Disease." Medical Principles and Practice, Volume 11, Number 12: 3-8 